[0212-7199 (2004) 21: 3; pp 135-137] ANALES DE MEDICINA INTERNA Copyright $\odot 2004$ ARAN EDICIONES, S.L.

An. Med. InTERna (Madrid) Vol. 21, N. ${ }^{\circ}$ 3, pp. 135-137, 2004

\title{
Enfermedad de Kikuchi-Fujimoto asociada a infección por virus de la parotiditis. A propósito de 1 caso
}

\author{
A. M. GÓMEZ GARCÍA, E. MARTÍNEZ HURTADO'1, I. RUIZ RIBERA \\ Servicio de Medicina Interna IV. Hospital Universitario Clínico San Carlos. ${ }^{I}$ Escuela \\ Militar de Sanidad. Ministerio de Defensa. Madrid
}

PAROTIDITIS VIRAL INFECTION ASSOCIATED WITH KIKUCHI-
FUJIMOTO DISEASE. REVIEW OF 1 CASE

\begin{abstract}
RESUMEN
La enfermedad de Kikuchi-Fujimoto o linfadenitis necrotizante histiocitaria es un proceso autolimitado del sistema linfático que afecta con más frecuencia a mujeres jóvenes. Clínicamente se caracteriza por la presencia de fiebre y de adenopatías, sobretodo cervicales. El diagnóstico se basa fundamentalmente en la biopsia del ganglio afectado, ya que a menudo los datos de laboratorio son normales. Es una enfermedad rara en España, siendo más frecuente en países orientales. Se trata de un proceso de evolución benigna, con resolución espontánea en semanas o meses, razón por la cual esta enfermedad podría estar infradiagnosticada. Es fundamental su distinción de los linfomas, dado que la enfermedad de Kikuchi no necesita tratamiento.
\end{abstract}

PALABRAS CLAVE: Linfadenitis necrotizante histiocitaria. Kikuchi-Fujimoto. Histiocitos atípicos. Virus de la parotiditis. Linfadenopatía cervical.

\begin{abstract}
Kikuchi-Fujimoto disease or necrotizing histiocytic lymphadenitis is a self-limited process of lymphatic system that affects more frequently young women. Fever and adenopathy, often cervical, are typical. Diagnosis is fundamentally based on the affected lymph node biopsy, since laboratory data are often normal. It's a very rare entity in Spain, being more frequent in Oriental countries. It's a benign evolution process, with a spontaneous healing in some weeks or months. This is the reason because of this disease could be infradiagnosed. It's very important the differential diagnosis with malignant lymphomas, because Kikuchi-Fujimoto disease doesn't need any treatment.
\end{abstract}

KEY WORDS: Hystiocitic necrotizing lymphadenitis. Kikuchi-Fujimoto. Atypical hystiocites. Parotiditis virus. Cervical lymphadenopathy.

Gómez García AM, Martínez Hurtado E, Ruiz Ribera I. Enfermedad de Kikuchi-Fujimoto asociada a infección por virus de la parotiditis. A propósito de 1 caso. An Med Interna (Madrid) 2004; 21: 135-137.

\section{INTRODUCCIÓN}

La linfadenitis necrotizante histiocítica es una rara entidad descrita por Kikuchi y por Fujimoto de forma independiente pero simultánea en Japón en 1972. Inicialmente se había descrito en países orientales y los casos comunicados en nuestro país son escasos, aunque en los últimos años se han publicado varios casos en Europa.

La patogenia de la enfermedad de Kikuchi-Fujimoto es desconocida, y se ha relacionado con numerosos agentes infecciosos. Aportamos el caso de un varón de 22 años de edad que presentó serología positiva para el virus de la parotiditis, siendo éste el primer caso del que tenemos noticia relacionado con este virus.

\section{CASO APORTADO}

Varón de 22 años de edad que acude a consultas por presentar desde hacía 4 meses una adenopatía en región laterocervical izquierda, dolorosa, que no disminuyó de tamaño con la toma de antibióticos ni AINE. Refería haber presentado cuadro de varios días de evolución de fiebre de hasta $38{ }^{\circ} \mathrm{C}$ y de sudoración nocturna profusa, coincidiendo con tos y molestias faríngeas, sintomatología que desapareció en unos días.

A la exploración el paciente presentaba una adenopatía en región laterocervical izquierda de $2 \mathrm{~cm}$. de diámetro, no adherida a planos superficiales ni profundos, no dolorosa a la palpación y de consistencia elástica. Además presentaba otras dos adenopatías de características similares, de aproximadamente $1,5 \mathrm{~cm}$ de diámetro, en región supraclavicular izquierda y región laterocervical derecha. El resto de la exploración no presentaba hallazgos de interés. 